\title{
KEANEKARAGAMAN SPESIES AVIFAUNA DIURNAL DI BEBERAPA TIPE HABITAT PADA AREAL IUPHHK-HTI PT HUTAN KETAPANG INDUSTRI KABUPATEN KETAPANG
}

\author{
(Species Diversity of Avifauna Diurnal in Some Habitat Types on The Area of IUPHHK-HTI \\ PT. Hutan Ketapang Industri Ketapang Regency)
}

\author{
Tomy Dwifortunata, Hari Prayogo, Sarma Siahaan \\ Fakultas Kehutanan Universitas Tanjungpura Pontianak. Jl. Daya Nasional Pontianak 78124 \\ Email: tomydwif@gmail.com
}

\begin{abstract}
Birds or Aves are members of vertebrates that have feathers and wings. Spreads from lowlands until highlands occupying various habitats, similarly in Kalimantan birds are found in various places. The goal of this research is to acquire biodiversity data of birds in certain types of the forest before and after operations in the region of PT Hutan Ketapang Industri. This research use the IPA (Index Point Abundance) method which is placed purposively on five types of habitat. The habitats are kerangas forest, peat swamp forest, dipterocarpus lowland forest, riparian and open wetland/flood plain. The research was conducted in the area before and after operational activity. The research shows the differences in results at each location. There are found 40 species of birds that belong to 23 families.
\end{abstract}

Keyword: Bird Diurnal, Diversity, Five Habitat Types

\section{PENDAHULUAN}

Burung atau aves adalah anggota kelompok hewan bertulang belakang (vertebrata) yang memiliki bulu dan sayap (Kuswanda, 2010). Burung merupakan salah satu jenis satwa liar yang banyak dimanfaatkan oleh manusia sebagai bahan makanan, binatang peliharaan, pemenuhan kebutuhan ekonomi dan estetika. Seiring dengan meningkatnya jumlah penduduk dan tingginya penggunaan jenis burung oleh manusia, mengakibatkan terjadinya tekanan spesies. Banyaknya manfaat yang dimiliki, manusia berupaya ingin memanfaatkan baik langsung maupun tidak langsung sehingga kelestarian spesies burung ini dapat terancam.

Konservasi burung di Indonesia saat ini masih terpusat pada kawasan konservasi seperti cagar alam, suaka margasatwa dan taman nasional. Burung merupakan satwa liar yang memiliki tingkat mobilitas yang tinggi dan mampu beradaptasi pada berbagai tipe habitat yang luas (Welty, 1982), sehingga upaya konservasi juga perlu dilakukan di kawasan lain, salah satunya adalah di hutan lindung. Menurut UU no 106/2018, hutan lindung ialah kawasan hutan yang karena keadaan sifat alamnya diperuntukkan guna mengatur tata air, pencegahan bencana banjir dan erosi serta pemeliharaan kesuburan tanah.

Burung merupakan salah satu komponen ekosistem yang memiliki peranan penting dalam mendukung berlansungnya kehidupan organisme. Keadaan ini dapat dilihat dari rantai makanan dan jaring-jaring kehidupan yang membentuk system kehidupannya dengan 
komponen ekosistem lainnya seperti tumbuhan dan serangga (Sawitri et al. 2010). keberadaan burung di suatu kawasan sangatlah penting, karena dapat mempengaruhi keberadaan dan persebaran jenis tumbuhan. Mengingat pentingnya peranan jenis burung dalam menjaga keseimbangan ekosistem maka penelitian tentang keanekaragaman jenis burung di PT. Hutan Ketapang Industri ini perlu dilakukan dan penelitian ini belum pernah dilakukan sebelumnya di lokasi tersebut.

PT. Hutan Ketapang Industri merupakan perusahaan swasta nasional yang bergerak dibidang pengusahaan hutan tanaman industry (HTI) yang berlokasi di Kabupaten Ketapang, Provinsi Kalimantan Barat dengan luas \pm 100.105 ha. Penelitian ini dilakukan pada beberapa tipe habitat yaitu habitat yang sudah dilakukan penanaman karet dan yang masih utuh berupa hutan alam. Tipe habitat yang akan dijadikan lokasi penelitian adalah hutan kerangas, hutan rawa gambut, hutan dipterocarps dataran rendah, riparian, lahan basah terbuka/dataran banjir. Tujuan penelitian ini untuk memproleh data keanekaragaman jenis burung pada beberapa tipe hutan sebelum dan sesudah kegiatan operasional dikawasan PT Hutan Ketapang Industri, dan juga Mendata kaitan antara jenis burung dan tipe habitat tempat tinggalnya.

\section{METODE PENELITIAN}

Penelitian dilakukan di lima tipe habitat sebelum dan sesudah kegiatan operasional diwilayah PT. Hutan Ketapang Industri Kecamatan Kendawangan Kabupaten Ketapang. Alat yang digunakan yaitu Binokuler, Buku identifikasi, Kamera, GPS, Tally sheet, dan jam tangan. Objek penelitian ini adalah satwa liar burung yang dijumpai di beberapa tipe hutan di wilayah PT. Hutan Ketapang Industri.

Metode yang digunakan yaitu metode IPA (Index Point Abundance). Pelaksanaan pengamatan dilakukan dengan cara diam pada titik tertentu kemudian berjalan lagi dan berhenti di titik tertentu lagi lalu mencatat perjumpaan terhadap burung.

Penetapan lokasi ditempatkan secara purposive meliputi; hutan kerangas, hutan rawa gambut, hutan diptherocarps dataran rendah, riparian, lahan basah terbuka/dataran banjir, dan dilakukan selama 1 bulan. Radius pengamatan untuk setiap titik sejauh 30 meter ke kiri dan 30 meter ke kanan dengan jarak antar titik 300 meter sebanyak 6 titik. Waktu pengamatan 20 menit, panjang transek $1500 \mathrm{~m}$. waktu pengamatan pagi pukul $06.00-09.00 \mathrm{WIB}$ dan sore pukul 15.00 -17.00 WIB.

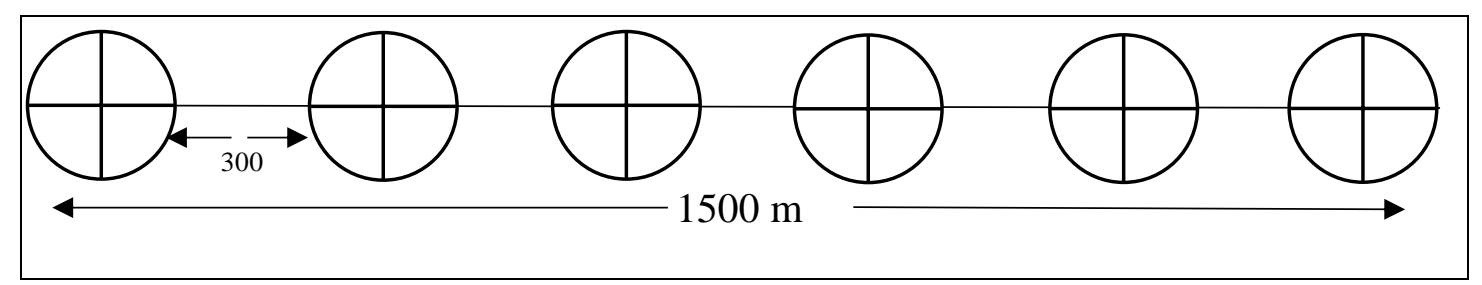

Gambar 1. Jalur pengamatan (line of observation) 
Analisis Data

Analisis data dilakukan menggunakan rumus menurut Odum (1983) yaitu:

Kepadatan spesies, Indeks Dominasi (Simpson's Index) / (Di), Indeks kekayaan jenis (Species Richness Index) I (d), Indeks keanekaragaman Shannon (Shannon - Wienner Index) / $(\bar{H})$, Indeks Kemerataan (Pielou's Evenness Index) / (e), dan Indeks Kesamaan Jenis (Similarity Index) / (IS).

\section{HASIL DAN PEMBAHASAN}

1. Keanekaragaman Jenis Burung Diurnal di Areal Sebelum Kegiatan Operasional

Area PT. Hutan Ketapang Industri
Ketapang dilima tipe habitat sebelum kegiatan operasional dijumpai sebanyak 26 jenis burung diurnal yang tergolong kedalam 14 suku (Family). Hutan Kerangas di jumpai sebanyak 10 jenis dengan jumlah individu 66, hutan rawa gambut di jumpai sebanyak 13 jenis dengan jumlah individu 76, hutan dipterocarps dataran rendah di jumpai sebanyak 10 jenis dengan individu 78, hutan riparian di jumpai sebanyak 10 jenis dengan jumlah individu 53, dan lahan basah terbuka/dataran banjir di jumpai sebanyak 10 jenis dengan jumlah individu 53. Pengamatan dilakukan pada pagi dan sore hari, keanekaragaman burung diurnal yang dilakukan di pagi hari disajikan pada tabel 1.

Tabel 1. Indeks Dominasi (Di), Indeks Kekayaan jenis (d), Indeks Keanekaragaman $(\bar{H})$, dan Indeks Kemerataan (e), burung diurnal yang dijumpai pada lima tipe habitat sebelum kegiatan operasional dikawasan PT Hutan Ketapang Industri Kabupaten Ketapang pada pagi hari (Dominance Index (Di), Richess index (d), diversity index $(H \bar{T})$, evenness index (e), diurnal birds found in five types habitat before operational activities in PT Hutan Ketapang Industri Ketapang Regency in the morning)

\begin{tabular}{|c|c|c|c|c|c|}
\hline Indeks & $\begin{array}{c}\text { Hutan } \\
\text { Kerangas }\end{array}$ & $\begin{array}{c}\text { Hutan } \\
\text { Rawa } \\
\text { Gambut }\end{array}$ & $\begin{array}{c}\text { Hutan } \\
\text { Dipterocarpa } \\
\text { Dataran } \\
\text { Rendah }\end{array}$ & Riparian & $\begin{array}{c}\text { Lahan Basah } \\
\text { Terbuka/Dataran } \\
\text { Banjir }\end{array}$ \\
\hline $\begin{array}{l}\text { Indeks Dominasi } \\
\text { (Di) }\end{array}$ & 0,81 & 0,73 & 1,88 & 0,54 & 0,63 \\
\hline $\begin{array}{l}\text { Indeks kekayaan } \\
\text { jenis (d) }\end{array}$ & 19,71 & 16,83 & 18,28 & 12,57 & 12,72 \\
\hline $\begin{array}{l}\text { Indeks } \\
\text { keanekaragaman }(\mathrm{H})\end{array}$ & 1,93 & 1,88 & 1,40 & 1,92 & 1,83 \\
\hline $\begin{array}{l}\text { Indeks } \\
\text { Kemerataan(e) }\end{array}$ & 1,93 & 1,97 & 1,80 & 2,02 & 1,79 \\
\hline
\end{tabular}

Sumber: data primer 2019

Menurut (Ferianita 2007) kisaran indeks dominan adalah 0-1 apabila nilai $\mathrm{Di}=0$ berarti tidak terdapat spesies yang mendominasi spesies yang lain atau struktur komnitas labil, karena tekanan ekologis. Pada tipe habitat sebelum kegiatan operasional Nilai indeks Dominasi (Di) pada tipe habitat hutan dipterocarps dataran rendah pada pagi hari dengan nilai $\mathrm{Di}=1.88$, Sedangkan 
untuk nilai indeks dominasi (Di) pada hutan kerangas pagi hari dengan nilai $\mathrm{Di}=0.81$, Indeks dominasi (Di) Pada tipe habitat hutan rawa gambut pagi hari dengan nilai $\mathrm{Di}=0.73$, Indeks dominasi (Di) pada tipe habitat hutan riparian pagi hari dengan nilai $\mathrm{Di}=0.54$, untuk indeks dominasi (Di) pada tipe habitat lahan basah terbuka/dataran banjir pagi hari dengan nilai $\mathrm{Di}=0.63$. Berdasarkan hasil perhitungan Indeks Dominasi (Di) jenis burung, diketahui bahwa pada tiap tipe habitat memiliki nilai Dominasi yang berbeda-beda dengan nilai yang tertinggi terdapat pada tipe habitat hutan dipterocarps dataran rendah hal ini dikarenakan jalur pengamatan pada tipe habitat hutan dipterocarps dataran rendah memiliki sumber pakan yang cukup bagi sebegian jenis burung dan berhubungan erat dengan kelimpahan yang tinggi.

Nilai indeks kekayaan jenis (d) dipengaruhi oleh dua factor yaitu jumlah jenis dan banyaknya individu untuk semua jenis, dimana semakin banyak jenis yang ditemukan maka akan semakin besar pula nilai indeks kekayaan jenisnya (d). Nilai kekayaan jenis pada tipe habitat sebelum kegiatan operasional habitat hutan kerangas pagi hari sebesar $d=19.71$. Nilai kekayaan jenis pada tipe habitat sebelum kegiatan operasional habitat Hutan Rawa Gambut pagi hari sebesar $\mathrm{d}=16.83$. Nilai kekayaan jenis pada tipe habitat sebelum kegiatan operasional habitat hutan dipterocarps dataran rendah pagi hari sebesar $d=18.28$. Nilai kekayaan jenis pada tipe habitat sebelum kegiatan operasional habitat hutan riparian pagi hari sebesar $d=12.57$. Nilai kekayaan jenis pada tipe habitat sebelum kegiatan operasional habitat Lahan Basah terbuka/dataran banjir pagi hari sebesar $\mathrm{d}=$ 12.72. Berdasarkan hasil Indeks Kekayaan jenis (d) tersebut dapat diketahui bahwa nilai yang tertinggi terdapat pada tipe habitat hutan hutan dipterocarps dataran rendah dikarenakan pada jalur pengamatan tersebut masih memiliki kerapatan vegetasi yang lebat, tipe habitat tersebut lebih menyediakan makanan dan tempat berlindung bagi burung didalam kawasan tersebut.

Keanekaragaman jenis menggambarkan tingginya tingkat keanekaragaan yang terdapat pada suatu kawasan, semakin tinggi nilai indeks keanekaragaman Janis $(\bar{H})$ maka semakin banyak jenis-jenis yang terdapat pada kawasan tersebut. Menurut Shannnon-Winer dalam Ferianita (2007) kisaran keanekaragaman jens $(\bar{H})$ antara 1-3. Kisaran nilai $(\bar{H})<1$ berarti keanekaragaman jenis rendah $(\bar{H})>1<3$ berarti keanekaragaman sedang dan jika > 3 berarti keanekaragaman tinggi. Pada tipe habitat sebelum kegiatan operasional diketahui bahwa pada habitat hutan kerangas pagi hari memiliki indeks keanekaragaman jenis $(\bar{H})$ dengan nilai $(\bar{H})=1.93$. Tipe habitat sebelum kegiatan operasional pada habitat hutan rawa gambut pagi hari memiliki indeks keanekaragaman jenis $(\bar{H})$ dengan nilai $(\bar{H})=1.88$. Tipe habitat sebelum kegiatan operasional pada habitat Hutan Dipterocarps Dataran Rendah pagi hari memiliki indeks 
keanekaragaman jenis $(\bar{H})$ dengan nilai $(\bar{H})=1.40$. Tipe habitat sebelum kegiatan operasional pada habitat hutan riparian pagi hari memiliki indeks keanekaragaman jenis $(\bar{H})$ dengan nilai $(\bar{H})=1.92$. Tipe habitat sebelum kegiatan operasional pada habitat Lahan Basah Terbuka/Dataran Banjir pagi hari memiliki indeks keanekaragaman jenis $(\bar{H})$ dengan nilai $(\bar{H})=1.83$. Berdasarkan hasil perhitungan Indeks Keanekaragaman Jenis yang tertinggi dibandingkan tipe habitat lainnya yaitu hutan rawa gambut. Keanekaragaman Jenis $(\bar{H})$ pada habitat ini dikategorikan keanekaragaman jenis sedang hal ini berhubungan erat dengan kerapatan vegetasi yang tinggi sehingga satwasatwa liar khususnya burung mencari makan dan menjadikan tempat singgah bahkan berkembang biak pada tipe habitat tersebut.

Indeks kemerataan jenis (e) dipengaruhi oleh besarnya nilai keanekaragaman suatu jenis dan jumlah seluruh jenis, artinya semakin tinggi nilai kelimpahan jenis maka penyebaran suatu jenis semakin merata dalam suatu kawasan tersebut. Menurut Odum (1993), indeks kemerataan jenis (e) berkisar antara $0-1$, jika e $>1$, maka seluruh jenis yang ada memiliki kelimpahan yang sama atau merata, sedangkan jika e $<1$, maka seluruh jenis yang ada kelimpahannya tidak merata. Berdasarkan data yang di peroleh dilapangan pada tipe habitat sebelum kegiatan operasional pada habitat hutan kerangas pagi hari mempunyai indeks kemerataan jenis sebesar $\mathrm{e}=1.93$. Tipe habitat sebelum kegiatan operasional pada habitat hutan rawa gambut pagi hari mempunyai indeks kemerataan jenis sebesar $\mathrm{e}=1.97$. Tipe habitat sebelum kegiatan operasional pada habitat hutan dipterocarps dataran rendah pagi hari mempunyai indeks kemerataan jenis sebesar $\mathrm{e}=1.80$. Tipe habitat sebelum kegiatan operasional pada habitat Hutan Riparian pagi mempunyai indeks kemerataan jenis sebesar $e=2.02$. Tipe habitat sebelum kegiatan operasional pada habitat lahan basah terbuka/dataran banjir pagi hari mempunya indeks kemerataan jenis sebesar $\mathrm{e}=1.79$. Berdasarkan nilai tersebut maka indeks kemerataan jenis (e) pada lima tipe habitat memiliki kelimpahan yang merata/sama hal ini disebabkan karena pada lima tipe habitat tersebut hampir memiliki tipe vegetasi yang hampir sama dan juga hampir memiliki sumber pakan yang mencukupi bagi tiap-tiap spesies burung. Pengamatan dilakukan pada pagi dan sore hari, keanekaragaman burung diurnal yang dilakukan di sore hari disajikan pada tabel 2 . 
Tabel 2. Indeks Dominasi (Di), Indeks Kekayaan Jenis (d), Indeks Keanekaragaman $(\bar{H})$, dan Indeks Kemerataan (e), burung diurnal yang dijumpai pada lima tipe habitat sebelum kegiatan operasional dikawasan PT Hutan Ketapang Industri Kabupaten Ketapang pada sore hari hari (Dominance Index (Di), Richess index $(d)$, diversity index $(H \overline{)}$, evenness index (e), diurnal bird found in five types habitat before operational activities in PT Hutan Ketapang Industri Ketapang Regency in the afternoon)

\begin{tabular}{lccccc}
\hline \multicolumn{1}{c}{ Indeks } & $\begin{array}{c}\text { Hutan } \\
\text { Kerangas }\end{array}$ & $\begin{array}{c}\text { Hutan } \\
\text { Rawa } \\
\text { Gambut }\end{array}$ & $\begin{array}{c}\text { Hutan } \\
\text { Dipterocarpa } \\
\text { Dataran } \\
\text { Rendah }\end{array}$ & Riparian & $\begin{array}{c}\text { Lahan Basah } \\
\text { Terbuka/Dataran } \\
\text { Banjir }\end{array}$ \\
\hline $\begin{array}{l}\text { Indeks Dominasi (Di) } \\
\begin{array}{l}\text { Indeks kekayaan jenis } \\
\text { (d) }\end{array}\end{array}$ & 1,35 & 0,55 & 1,19 & 0,84 & 0,62 \\
$\begin{array}{l}\text { Indeks } \\
\text { keanekaragaman (H) }\end{array}$ & 13,76 & 19,22 & 21,90 & 13,42 & 13,27 \\
Indeks Kemerataan(e) & 1,40 & 2,11 & 1,76 & 1,68 & 1,87 \\
\hline
\end{tabular}

Sumber: data primer 2019

Nilai indeks Dominasi (Di) pada tipe habitat hutan dipterocarps dataran rendah pada sore hari dengan nilai $\mathrm{Di}=$ 1.19, Sedangkan untuk nilai indeks dominasi (Di) pada hutan kerangas sore hari dengan nilai $\mathrm{Di}=1.35$. Indeks dominasi (Di) Pada tipe habitat hutan rawa gambut sore hari dengan nilai $\mathrm{Di}=$ 0.55 . Indeks dominasi (Di) pada tipe habitat hutan riparian sore hari dengan nilai $\mathrm{Di}=0.84$. untuk indeks dominasi (Di) pada tipe habitat lahan basah terbuka/dataran banjir sore hari dengan nilai $\mathrm{Di}=0.62$.

Nilai kekayaan jenis pada tipe habitat sebelum kegiatan operasional habitat Hutan kerangas sore hari sebesar $\mathrm{d}=13.76$. Nilai kekayaan jenis pada tipe habitat sebelum kegiatan operasional habitat hutan rawa gambut sore hari sebesar $d=19.22$. Nilai kekayaan jenis pada tipe habitat sebelum kegiatan operasional habitat hutan dipterocarps dataran rendah sore hari sebesar $\mathrm{d}=$
21.90. Nilai kekayaan jenis pada tipe habitat sebelum kegiatan operasional habitat hutan riparian sore hari sebesar $\mathrm{d}=13.42$. Nilai kekayaan jenis pada tipe habitat sebelum kegiatan operasional habitat lahan basah terbuka/dataran banjir sore hari sebesar $\mathrm{d}=13.27$.

Diketahui bahwa pada habitat hutan kerangas sore hari memiliki indeks keanekaragaman jenis $(\bar{H})$ dengan nilai $(\bar{H})=1.40$. Tipe habitat sebelum kegiatan operasional pada habitat hutan rawa gambut sore hari memiliki indeks keanekaragaman jenis $(\bar{H})$ dengan nilai $(\bar{H})=2.11$. Tipe habitat sebelum kegiatan operasional pada habitat hutan dipterocarps dataran rendah sore hari memiliki indeks keanekaragaman jenis $(\bar{H})$ dengan nilai $(\bar{H})=1.76$. Tipe habitat sebelum kegiatan operasional pada habitat hutan riparian sore hari memiliki indeks keanekaragaman jenis $(\bar{H})$ dengan nilai $(\bar{H})=1.68$. Tipe habitat sebelum kegiatan operasional pada 
habitat Lahan Basah Terbuka/Dataran Banjir sore hari memiliki indeks keanekaragaman jenis $(\bar{H})$ dengan nilai $(\bar{H})=1.87$.

Tipe habitat sebelum kegiatan operasional pada habitat hutan kerangas sore hari mempunyai indeks kemerataan jenis sebesar $e=2.00$. Tipe habitat sebelum kegiatan operasional pada habitat hutan rawa gambut sore hari mempunyai indeks kemerataan jenis sebesar $\mathrm{e}=2.11$. Tipe habitat sebelum kegiatan operasional pada habitat hutan dipterocarps dataran rendah sore hari mempunyai indeks kemerataan jenis sebesar $\mathrm{e}=1.95$. Tipe habitat sebelum kegiatan operasional pada habitat hutan riparian sore hari mempunyai indeks kemerataan jenis sebesar e $=1.99$. Tipe habitat sebelum kegiatan operasional pada habitat lahan basah terbuka/dataran banjir sore hari mempunya indeks kemerataan jenis sebesar $\mathrm{e}=2.07$.

\section{Keanekaragaman Jenis Burung Diurnal di Areal Sesudah Kegiatan Operasional}

Sesudah kegiatan operasional pada lima tipe habitat dijumpai sebanyak 20 jenis burung diurnal yang tergolong kedalam 15 suku (Family). Pada pada hutan Kerangas di jumpai sebanyak 9 jenis dengan jumlah individu 75, hutan Rawa Gambut di jumpai sebanyak 9 jenis dengan jumlah individu 52, hutan dipterocarps dataran rendah di jumpai sebanyak 8 jenis dengan individu 74 , hutan riparian di jumpai sebanyak 9 jenis dengan jumlah individu 75, dan lahan basah terbuka/dataran banjir di jumpai sebanyak 11 jenis dengan jumlah individu 102. Pengamatan dilakukan pada pagi dan sore hari, keanekaragaman burung diurnal yang dilakukan di pagi hari disajikan pada tabel 3.

Tabel 3.Indeks Dominasi (Di), Indeks Kekayaan Jenis (d), Indeks Keanekaragaman $(\bar{H})$, dan Indeks Kemerataan (e), burung diurnal yang dijumpai pada lima tipe habitat sesudah kegiatan operasional dikawasan PT Hutan Ketapang Industri Kabupaten Ketapang pada pagi hari hari (Dominance Index (Di), Richess index (d), diversity index $(H \overline{)}$, evenness index (e), diurnal birds found in five types habitat after operational activities in PT Hutan Ketapang Industri District Ketapang in the morning Day)

\begin{tabular}{|c|c|c|c|c|c|}
\hline Indeks & $\begin{array}{l}\text { Hutan } \\
\text { Kerangas }\end{array}$ & $\begin{array}{l}\text { Hutan } \\
\text { Rawa } \\
\text { Gambut }\end{array}$ & $\begin{array}{c}\text { Hutan } \\
\text { Dipterocarps } \\
\text { Dataran } \\
\text { Rendah } \\
\end{array}$ & Riparian & $\begin{array}{c}\text { Lahan Basah } \\
\text { Terbuka/Dataran } \\
\text { Banjir }\end{array}$ \\
\hline $\begin{array}{l}\text { Indeks Dominasi } \\
\text { (Di) }\end{array}$ & 0,80 & 0,67 & 0,83 & 0,62 & 1,12 \\
\hline $\begin{array}{l}\text { Indeks kekayaan } \\
\text { jenis (d) }\end{array}$ & 20,46 & 14,89 & 19,48 & 19,84 & 24,72 \\
\hline $\begin{array}{l}\text { Indeks } \\
\text { keanekaragaman }(\mathrm{H})\end{array}$ & 1,94 & 1,87 & 1,87 & 2,09 & 1,87 \\
\hline $\begin{array}{l}\text { Indeks Kemerataan } \\
\text { (e) }\end{array}$ & 2,15 & 2,07 & 2,07 & 2,19 & 2,03 \\
\hline
\end{tabular}

Sumber: data primer 2019 
Menurut (Ferianita 2007) kisaran indeks dominan adalah 0-1 apabila nilai $\mathrm{Di}=0$ berarti tidak terdapat spesies yang mendominasi spesies yang lain atau struktur komnitas labil, karena tekanan ekologis. Tipe habitat sesudah kegiatan operasional nilai indeks Dominasi (Di) pada tipe habitat lahan basah terbuka/dataran banjir pagi hari dengan nilai $\mathrm{Di}=1.12$, sedangkan untuk indeks Dominasi (Di) pada tipe habitat hutan kerangas pagi hari dengan nilai $\mathrm{Di}=$ 0.80. Indeks Dominasi (Di) pada tipe habitat Hutan rawa gambut pagi hari dengan nilai $\mathrm{Di}=0.67$. Indeks Dominasi (Di) pada tipe habitat hutan dipterocarps dataran rendah pagi hari dengan nilai Di $=0.83$. Indeks Dominasi (Di) pada tipe habitat hutan riparian pagi hari dengan nilai $\mathrm{Di}=0.62$. Berdasarkan hasil perhitungan Indeks Dominasi (Di) jenis burung, diketahui bahwa pada tiap tipe habitat memiliki nilai Dominasi yang berbeda-beda begitu juga pada habitat sesudah kegiatan operasional dengan nilai yang tertinggi terdapat pada tipe habitat lahan basah terbuka/dataran banjir hal ini dikarenakan pada habitat ini jalur pengamatan diletakan berdekatan dengan hutan disampingnya sehingga memungkinkan burung untuk mencari makan berupa biji-bijian dan menjadikan tempat singgah pada jalur pengamatan tersebut.

Nilai indeks kekayaan jenis (d) dipengaruhi oleh dua faktor yaitu jumlah jenis dan banyaknya individu untuk semua jenis, dimana semakin banyak jenis yang ditemukan maka akan semakin besar pula nilai indeks kekayaan jenisnya (d). Nilai kekayaan jenis pada tipe habitat sesudah kegiatan operasional habitat hutan kerangas pagi hari sebesar $d=20.46$. nilai kekayaan jenis pada tipe habitat sesudah kegiatan operasional habitat hutan rawa gambut pagi hari sebesar $d=14.89$. Nilai kekayaan jenis pada tipe habitat sesudah kegiatan operasional habitat hutan dipterocarps dataran rendah pagi hari sebesar $d=19.48$. Nilai kekayaan jenis pada tipe habitat sesudah kegiatan operasional habitat hutan riparian pagi hari sebesar $d=19.84$. Nilai kekayaan jenis pada tipe habitat sesudah kegiatan operasional habitat lahan basah terbuka/dataran banjir pagi hari sebesar $\mathrm{d}=$ 24.72. Berdasarkan hasil Indeks Kekayaan jenis (d) tersebut dapat diketahui bahwa nilai yang tertinggi terdapat pada tipe habitat hutan kerangas dikarenakan pada jalur pengamatan tersebut banyak ditumbuhi jenis tumbuhan kacang-kacangan dan tumbuhan yang menghasilkan biji-bijian sehingga memungkinkan burung untuk mencari makan pada jalur pengamatan tersebut dan juga pada habitat ini banyak di jumpai burung yang hidup secara berkelompok seperti tekukur biasa (Streptopeli chinensis), kekep babi (Artamus leucorhynchus), dan merbah cerukcuk (Pycnonotus goiavier).

Keanekaragaman jenis menggambarkan tingginya tingkat keanekaragaan yang terdapat pada suatu kawasan. Semakin tinggi nilai indeks keanekaragaman Janis $(\bar{H})$ maka semakin banyak jenis-jenis yang terdapat pada kawasan tersebut. Menurut 
Shannnon-Winer dalam Ferianita (2007) kisaran keanekaragaman jens $(\bar{H})$ antara 1-3. Kisaran nilai $(\bar{H})<1$ berarti keanekaragaman jenis rendah $(\bar{H})>1<3$ berarti keanekaragaman sedang dan jika > 3 berarti keanekaragaman tinggi. Pada tipe habitat sesudah kegiatan operasional diketahui bahwa pada habitat hutan kerangas pagi hari memiliki indeks keanekaragaman jenis $(\bar{H})$ dengan nilai $(\bar{H})=1.94$. Tipe habitat sesudah kegiatan operasional pada habitat hutan rawa gambut pagi hari memiliki indeks keanekaragaman jenis $(\bar{H})$ dengan nilai $(\bar{H})=1.87$. Tipe habitat sesudah kegiatan operasional pada habitat hutan dipterocarps dataran rendah pagi hari memiliki indeks keanekaragaman jenis $(\bar{H})$ dengan nilai $(\bar{H})=1.87$. Tipe habitat sesudah kegiatan operasional pada habitat hutan riparian pagi hari memiliki indeks keanekaragaman jenis $(\bar{H})$ dengan nilai $(\bar{H})=2.09$. tipe habitat sesudah kegiatan operasional pada habitat lahan basah terbuka/dataran banjir pagi hari memiliki indeks keanekaragaman jenis $(\bar{H})$ dengan nilai $(\bar{H})=1.87$. Berdasarkan hasil perhitungan Indeks Keanekaragaman Jenis yang tertinggi dibandingkan tipe habitat lainnya yaitu hutan riparian. Keanekaragaman Jenis $(\bar{H})$ pada haitat ini dikategorikan keanekaragaman jenis sedang, hal ini dikarenakan jalur pengamatan pada habitat ini mendekati sumber air dimana selain faktor pakan burung juga menyukai daerah yang terdapat sumber air.

Indeks kemerataan jenis (e) dipengaruhi oleh besarnya nilai keanekaragaman suatu jenis dan jumlah seluruh jenis, artinya semakin tinggi nilai kelimpahan jenis maka penyebaran suatu jenis semakin merata dalam suatu kawasan tersebut. Menurut Odum (1993), indeks kemerataan jenis (e) berkisar antara $0-1$, jika e $>1$, maka seluruh jenis yang ada memiliki kelimpahan yang sama atau merata, sedangkan jika e $<1$, maka seluruh jenis yang ada kelimpahannya tidak merata. Tipe habitat sesudah kegiatan operasional pada habitat hutan kerangas pagi hari mempunyai indeks kemerataan jenis sebesar $e=2.15$. Tipe habitat sesudah kegiatan operasional pada habitat hutan rawa Gambut pagi hari mempunyai indeks kemerataan jenis sebesar $e=2.07$. Tipe habitat sesudah kegiatan operasional pada habitat hutan dipterocarps dataran rendah pagi hari mempunyai indeks kemerataan jenis sebesar $e=2.07$. Tipe habitat sesudah kegiatan operasional pada habitat hutan riparian pagi mempunyai indeks kemerataan jenis sebesar $e=2.19$. Tipe habitat sesudah kegiatan operasional pada habitat lahan basah terbuka/dataran banjir pagi hari mempunyai indeks kemerataan jenis sebesar $\mathrm{e}=2.03$. kemerataan jenis yang rendah disebabkan adanya persaingan dalam memanfaatkan sumberdaya yang ada, sedangkan kemerataan jenis yang tinggi menunjukan bahwa jenis tersebut mampu bersaing dan dapat menyesuaikan diri dengan habitat serta ketersediaan pakan yang melimpah di daerah tersebut. Berdasarkan nilai tersebut maka indeks kemerataan jenis 
(e) pada lima tipe habitat memiliki kelimpahan yang merata/sama hal ini disebabkan karena pada lima tipe habitat sesudah kegiatan operasional tanaman karet yang menjadi jalur pengamatan tidak terlalu jauh berbeda kerapatan vegetasinya yaitu tahun tanam 20162017. Pengamatan dilakukan pada pagi dan sore hari, keanekaragaman burung diurnal yang dilakukan di sore hari disajikan pada tabel 4.

Tabel 4. Indeks Dominasi (Di), Indeks Kekayaan Jenis (d), Indeks Keanekaragaman $(\bar{H})$, dan Indeks Kemerataan (e), burung diurnal yang dijumpai pada lima tipe habitat sesudah kegiatan operasional dikawasan PT Hutan Ketapang Industri Kabupaten Ketapang pada sore hari hari (Dominance Index (Di), Richess index (d), diversity index $(H \overline{)})$, evenness index (e), diurnal birds found in five types habitat after operational activities in PT Hutan Ketapang Industri Ketapang Regency in the afternoon)

\begin{tabular}{|c|c|c|c|c|c|}
\hline Indeks & $\begin{array}{c}\text { Hutan } \\
\text { Kerangas }\end{array}$ & $\begin{array}{c}\text { Hutan } \\
\text { Rawa } \\
\text { Gambut }\end{array}$ & $\begin{array}{c}\text { Hutan } \\
\text { Dipterocarps } \\
\text { Dataran } \\
\text { Rendah }\end{array}$ & Riparian & $\begin{array}{c}\text { Lahan Basah } \\
\text { Terbuka/Dataran } \\
\text { Banjir }\end{array}$ \\
\hline $\begin{array}{l}\text { Indeks Dominasi } \\
\text { (Di) }\end{array}$ & 0,83 & 1,07 & 1,19 & 0,66 & 1,23 \\
\hline $\begin{array}{l}\text { Indeks kekayaan } \\
\text { jenis (d) }\end{array}$ & 17,63 & 12,66 & 18,78 & 16,97 & 25,64 \\
\hline $\begin{array}{l}\text { Indeks } \\
\text { keanekaragaman }(\mathrm{H})\end{array}$ & 1,83 & 1,49 & 1,67 & 1,94 & 1,83 \\
\hline $\begin{array}{l}\text { Indeks Kemerataan } \\
\text { (e) }\end{array}$ & 2,17 & 2,13 & 2,15 & 2,14 & 2,03 \\
\hline
\end{tabular}

Sumber: data primer 2019

Tipe habitat sesudah kegiatan operasional nilai indeks Dominasi (Di) pada tipe habitat lahan basah terbuka/dataran banjir sore hari dengan nilai $\mathrm{Di}=1.23$. Sedangkan untuk indeks Dominasi (Di) pada tipe habitat hutan kerangas sore hari dengan nilai $\mathrm{Di}=0.83$. Indeks Dominasi (Di) pada tipe habitat hutan rawa gambut sore hari dengan nilai $\mathrm{Di}=1.07$. Indeks Dominasi (Di) pada tipe habitat hutan dipterocarps dataran rendah sore hari dengan nilai $\mathrm{Di}=1.19$. Indeks Dominasi (Di) pada tipe habitat hutan riparian sore hari dengan nilai $\mathrm{Di}=0.66$.

Nilai kekayaan jenis pada tipe habitat sesudah kegiatan operasional habitat hutan kerangas sore hari sebesar $\mathrm{d}=17.63$. nilai kekayaan jenis pada tipe habitat sesudah kegiatan operasional habitat hutan rawa gambut sore hari sebesar $d=12.66$. Nilai kekayaan jenis pada tipe habitat sesudah kegiatan operasional habitat hutan dipterocarps dataran rendah sore hari sebesar $\mathrm{d}=18.78$. Nilai kekayaan jenis pada tipe habitat sesudah kegiatan operasional habitat hutan riparian sore hari sebesar $\mathrm{d}=$ 16.97. Nilai kekayaan jenis pada tipe habitat sesudah kegiatan operasional habitat lahan basah terbuka/dataran banjir sore hari sebesar $\mathrm{d}=1.83$.

Tipe habitat sesudah kegiatan operasional diketahui bahwa pada habitat hutan kerangas sore hari memiliki indeks keanekaragaman jenis $(\bar{H})$ dengan nilai 
$(\bar{H})=1.83$. Tipe habitat sesudah kegiatan operasional pada habitat hutan rawa gambut sore hari memiliki indeks keanekaragaman jenis $(\bar{H})$ dengan nilai $(\bar{H})=1.49$. Tipe habitat sesudah kegiatan operasional pada habitat hutan dipterocarps dataran rendah sore hari memiliki indeks keanekaragaman jenis $(\bar{H})$ dengan nilai $(\bar{H})=1.67$. Tipe habitat sesudah kegiatan operasional pada habitat hutan riparian sore hari memiliki indeks keanekaragaman jenis $(\bar{H})$ dengan nilai $(\bar{H})=1.94$. tipe habitat sesudah kegiatan operasional pada habitat lahan basah terbuka/dataran banjir sore hari memiliki indeks keanekaragaman jenis $(\bar{H})$ dengan nilai $(\bar{H})=1.83$.

Tipe habitat sesudah kegiatan operasional pada habitat hutan kerangas sore hari mempunyai indeks kemerataan jenis sebesar $e=2.17$. Tipe habitat sesudah kegiatan operasional pada habitat hutan rawa gambut sore hari mempunyai indeks kemerataan jenis sebesar $\mathrm{e}=2.13$. Tipe habitat sesudah kegiatan operasional pada habitat hutan dipterocarps dataran rendah sore hari mempunyai indeks kemerataan jenis sebesar $e=2.15$. Tipe habitat sesudah kegiatan operasional pada habitat hutan riparian sore hari mempunyai indeks kemerataan jenis sebesar $e=2.14$. Tipe habitat sesudah kegiatan operasional pada habitat lahan basah terbuka/dataran banjir sore hari mempunyai indeks kemerataan jenis sebesar $\mathrm{e}=2.03$.

\section{Kesimpulan}

Berdasarkan hasil pengamatan yang dilakukan di lokasi penelitiaan didalam wilayah PT. Hutan Ketapang Industri Kabupaten Ketapang di lima tipe habitat yang tersebar yaitu hutan dipterocarpa dataran rendah, hutan kerangas, riparian, hutan rawa gambut, dan lahan basah terbuka/dataran banjir. Jenis burung diurnal yang berhasil ditemukan tercatat sebanyak 40 jenis yang tergolong kedalam 23 Famili. Keanekaragaman jenis burung diurnal yang tertinggi terdapat pada area sebelum kegiatan operasional yaitu pada hutan rawa gambut dengan nilai pagi hari $(\bar{H})=1.88$ dan sore hari $(\bar{H})=2.11$ sedangkan pada habitat sesudah kegiatan operasional yaitu pada hutan riparian dengan nilai pagi hari $(\bar{H})=2.09$ dan sore hari $(\bar{H})=1.94$. Keanekaragaman jenis burung diurnal pada habitat sebelum dan sesudah kegiatan operasional ini dikategorikan keanekaragaman jenis sedang, hal ini berkaitan erat dengan kerapatan vegetasi yang tinggi sehingga satwa-satwa liar khususnya burung mencari makan dan menjadikan tempat singgah pada jalur tersebut.

\section{Ucapan Terima Kasih}

Penulis mengucapkan terima kasih kepada pihak PT. Hutan Ketapang Industri yang telah memfasilitasi dan memberi tempat penelitian.

\section{DAFTAR PUSTAKA}

Alikodra HS. 2002. Pengelolaan Satwa Liar jilid 1. Departemen Pendidikan dan Kebudayaan Direktorat Jendral Pendidikan Tinggi Riset Antar Universitas Ilmu Hayati Institut Pertanian Bogor.

CITES. The Conservation on International Trade in Endangered Species of Wld Faauna and Flora (2018)

Ferianita FM. 2007. Metode Sampling Bioekologi. PT. Bumi Aksara, Yogyakarta. 
IUCN. Red List Categories and Criteria Version 3.1 Second Edition (2018)

Kuswanda W. 2010. Pengaruh Komposisi Tumbuhan Terhadap Populasi Burung di Taman Nasional Batang Gadis, Sumatera Utara. Balai Penelitian Kehutanan Aek Nauli. Penelitian Hutan Dan Konservasi Alam 117(2):193-203.

MacKinnon JK, Phillips K, Bas VB. 2010. Seri Panduan Lapang BurungBurung di Sumatera, Jawa, Bali dan Kalimantan (Termasuk Sabah, Sarawak dan Brunai Darussalam). Pusat Panelitian Dan Pengembangan Biologi LIPI. Bogor.
Odum EP. 1993. Dasar-dasar Ekologi. Edisi ketiga. Gadjah Mada University Press. Yogyakarta.

Sawitri R, Mukhtar A.S, dan Iskandar S. 2010. Status Konservasi Mamalia dan Burung di Taman Nasional Merbabu. Jurnal Penelitian Hutan Dan Konservasi Alam. 117 (3):227239.

Welty JC. 1982. The Life of Bird. 3nd Edition. Saunders College Publishing. Philadelpphia: Philadelphia. 